\title{
Lumbar Disc Herniation Presented with Contralateral Symptoms
}

\author{
Pius Kim, M.D., ${ }^{1}$ Chang II Ju, M.D., Ph.D., Hyeun Sung Kim, M.D., Ph.D., ${ }^{2}$ Seok Won Kim, M.D., Ph.D. \\ Department of Neurosurgery, College of Medicine, Chosun University, Gwangju, Korea \\ Department of Neurosurgery, ${ }^{2}$ Suwon Nanoori Hospital, Suwon, Korea
}

Objective : This study aimed to unravel the putative mechanism underlying the neurologic deficits contralateral to the side with lumbar disc herniation (LDH) and to elucidate the treatment for this condition.

Methods : From January 2009 to June 2015, 8 patients with LDH with predominantly contralateral neurologic deficits underwent surgical treatment on the side with LDH with or without decompressing the symptomatic side. A retrospective review of charts and radiological records of these 8 patients was performed. The putative mechanisms underlying the associated contralateral neurological deficits, magnetic resonance imaging (MRI), electromyography (EMG), and the adequate surgical approach are discussed here.

Results : MRI revealed a similar laterally skewed paramedian disc herniation, with the apex deviated from the symptomatic side rather than directly compressing the nerve root; this condition may generate a contralateral traction force. EMG revealed radiculopathies in both sides of 6 patients and in the herniated side of 2 patients. Based on EMG findings and the existence of suspicious lateral recess stenosis of the symptomatic side, 6 patients underwent bilateral decompression of nerve roots and 2 were subjected to a microscopic discectomy to treat the asymptomatic disc herniation. No specific conditions such as venous congestion, nerve root anomaly or epidural lipomatosis were observed, which may be considered the putative pathomechanism causing the contralateral neurological deficits. The symptoms resolved significantly after surgery.

Conclusion : The traction force generated on the contralateral side and lateral recess stenosis, rather than direct compression, may cause the contralateral neurologic deficits observed in LDH.

Key Words : Lumbar · Herniated disk · Contralateral.

\section{INTRODUCTION}

Lumbar disc herniation (LDH) is the most common cause of radiculopathy and myelopathy wherein nerve root compression is on the same side as the presented symptoms. How- ever, spine surgeons have sometimes reported cases of LDH causing predominantly contralateral neurologic deficits.

Contralateral LDH without any significant abnormality on the symptomatic side on radiological studies can be an embarrassing situation, and spine surgeons hesitate to perform

- Received : October 25, 2016 • Accepted : December 23, 2016

- Address for reprints : Seok Won Kim, M.D., Ph.D.

Department of Neurosurgery, College of Medicine, Chosun University, 365 Pilmun-daero, Dong-gu, Gwangju 61453, Korea

Tel : +82-62-220-3126, Fax : +82-62-227-4575, E-mail : chosunns@chosun.ac.kr

This is an Open Access article distributed under the terms of the Creative Commons Attribution Non-Commercial License (http://creativecommons.org/licenses/by-nc/4.0) which permits unrestricted non-commercial use, distribution, and reproduction in any medium, provided the original work is properly cited. 
surgery due to the risk of failed surgeries.

In these cases, it is difficult to ensure the relief of symptoms without performing a decompression on the symptomatic side. Several authors have reported patients who presented contralateral symptoms caused by $\mathrm{LDH}^{1,3,8,16)}$. However, the exact mechanisms underlying this clinical condition are still not well understood.

In the present study, we report several cases of LDH presented with contralateral symptoms.

The putative mechanisms underlying the clinical features of this condition and the adequate surgical approach to treat this condition are also discussed.

\section{MATERIALS AND METHODS}

The present report is a retrospective study performed on the medical charts and radiographic records of patients presenting neurologic deficits contralateral to the side of LDH. From January 2009 to June 2015, 8 patients who showed neurologic deficits contralateral to the side of LDH underwent surgical treatment performed by two surgeons at a single center. Preoperative work-up included plain X-ray imaging, magnetic resonance imaging (MRI), and electromyography (EMG).

The patients ( 7 men and 1 woman), aged 21-68 years (mean age : 50.0 years), presented lesions ranging from $\mathrm{L} 2-3$ to $\mathrm{L} 4-5$ levels.
All patients met the following inclusion criteria :

1) No history of previous lumbar spine surgery

2) Single-level unilateral LDH presented with predominant contralateral symptoms

3) No large central type LDH, or significant instability

All patients have been assessed for at least 6 months and their mean follow-up period was 12 months.

The symptoms and signs of the patients, the imaging findings, including those of MRI, EMG, surgical approach, and clinical outcome, were evaluated.

\section{RESULTS}

All patients presented with dominant symptoms contralateral to the side of disc herniation. Seven men and 1 woman aged 21 to 68 years (mean age : 50.0 years) were retrospectively analyzed.

The affected levels varied from $\mathrm{L} 2-3(\mathrm{n}=2), \mathrm{L} 3-4(\mathrm{n}=1)$ and L4-5 ( $\mathrm{n}=5)$.

Basic characteristics of the patients are reported in Table 1. Most patients (7 of 8; 88\%) showed similar MRI findings : no direct compression was noted on the herniation and contralateral symptomatic sides; however, the apex of disc herniation was deviated toward the lateral, not medial, part.

Two patients (case 1 and 2) who presented L2-3 disc herniation and both radiculopathies underwent interbody fusion for

Table 1. Demographics of the patients

\begin{tabular}{|c|c|c|c|c|c|c|c|}
\hline Case & Age/sex & Level & Symptom & MRI finding & EMG & Operation & $\begin{array}{c}\text { Result } \\
\text { (MacNab's criteria) }\end{array}$ \\
\hline 1 & $67 / M$ & L2-3 & $\begin{array}{l}\text { Motor weakness } \\
\quad(\mathrm{Rt})\end{array}$ & $\mathrm{Lt}$ & Both & PLIF (both) & Excellent \\
\hline 2 & $45 / M$ & L2-3 & Pain (Lt) & Rt & Both & PLIF (both) & Excellent \\
\hline 3 & $50 / \mathrm{M}$ & L3-4 & Pain (Rt) & $\mathrm{Lt}$ & $L t$ & Lt (discectomy) & Good \\
\hline 4 & $23 / F$ & $\lfloor 4-5$ & Pain (Rt) & $\mathrm{Lt}$ & $\mathrm{Lt}$ & Lt (discectomy) & Excellent \\
\hline 5 & $58 / \mathrm{M}$ & $\lfloor 4-5$ & Pain (Rt) & $\mathrm{Lt}$ & Both & $\begin{array}{l}\text { Discectomy\&contralateral } \\
\text { decompression }\end{array}$ & Excellent \\
\hline 6 & $54 / M$ & $\lfloor 4-5$ & Pain (Lt) & Rt & Both & $\begin{array}{l}\text { Discectomy\&contralateral } \\
\text { decompression }\end{array}$ & Good \\
\hline 7 & $35 / M$ & $\lfloor 4-5$ & Pain (Rt) & $\mathrm{Lt}$ & Both & $\begin{array}{l}\text { Discectomy\&contralateral } \\
\text { decompression }\end{array}$ & Excellent \\
\hline 8 & $68 / M$ & $\lfloor 4-5$ & Pain (Lt) & Rt & Both & $\begin{array}{l}\text { Discectomy\&contralateral } \\
\text { decompression }\end{array}$ & Excellent \\
\hline
\end{tabular}

MRI : magnetic resonance imaging, EMG : electromyography, Lt : left, Rt : right, PLIF : posterior lumbar interbody fusion 

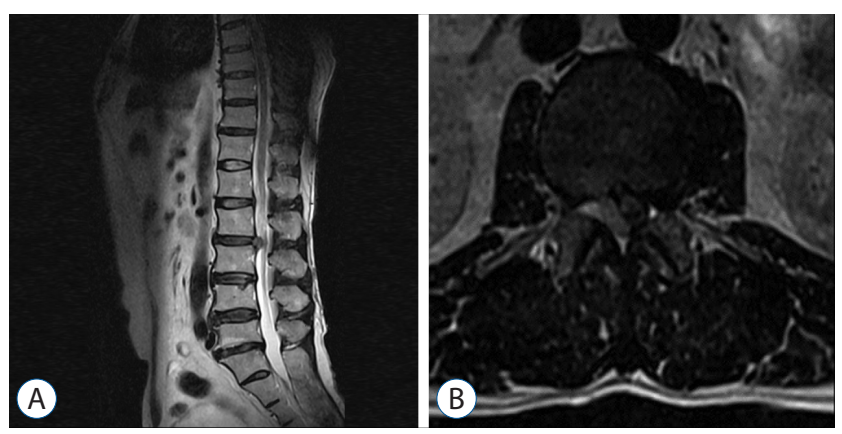

Fig. 1. A 67-year-old male patient presented with right leg motor weakness. A and B : T2-weighted sagittal and axial magnetic resonance images show left paracentral disc herniation with the apex deviated to the left.

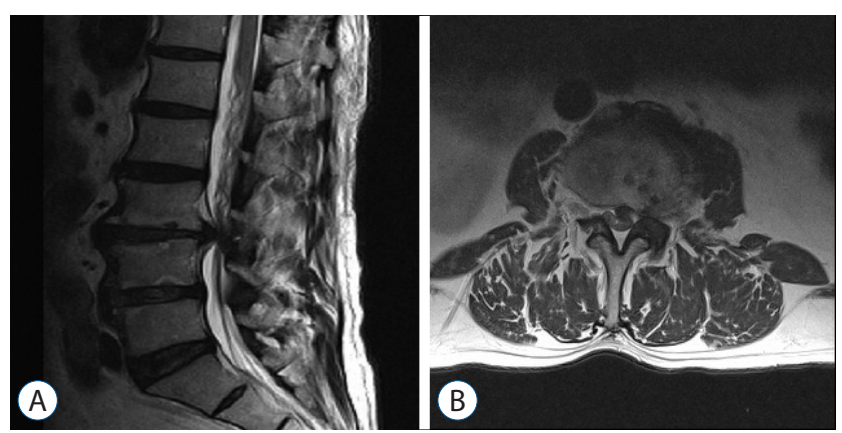

Fig. 2. A 50-year-old male patient presented with right leg pain. A and B : T2-weighted sagittal and axial magnetic resonance images reveal left paracentral disc herniation with the apex deviated to the left. Neither of the nerve roots are directly compressed.

narrow lamina width (Fig. 1).

Two patients (case 3 and 4) with pain radiating towards the right leg confirmed with left-side radiculopathy and left-side herniation on EMG underwent microscopic discectomy using the left side interlaminar approach without contralateral fenestration (Fig. 2). There were no preoperative findings of significant lateral recess stenosis in these 2 patients. Four patients (case 5-8) confirmed with both side radiculopathies on EMG, with suspicious contralateral lateral recess stenosis, underwent microscopic discectomy and fenestration for decompression contralateral to the symptomatic side.

The symptoms and signs improved significantly after surgery. All patients achieved a good, or excellent, outcome according to the modified MacNab's criteria assessed 6 months after surgery. Comparison of leg pain before and after surgery showed significant improvement in 7 patients after 6 months of surgery. Prior to surgery, the mean leg pain score (visual analogue scale) was $7.2 \pm 1.5$, which decreased to $2.5 \pm 1.0$ after 6 months of surgery. In one patient who showed contralateral motor weakness before surgery (case 1), the motor weakness was completely resolved in the 6-month follow-up.

\section{DISCUSSION}

It is well known that the presence of $\mathrm{LDH}$ on radiological studies is not always the cause of myelopathy or radiculopathy ${ }^{7,15)}$.

Especially, the development of MRI can detect the bulges or protrusions in people with low back pain coincidentally. However, the presence of a herniated disc on an imaging study does not guarantee the exact cause of the patient's symptoms and signs. Most lumbar radiculopathies are caused by root compression, most commonly from herniated lumbar discs or degenerative lumbar spine disease, such as the spinal stenosis or bony hypertrophy. Although MRI is sensitive enough to detect these anatomical changes that cause radiculopathy, this approach cannot provide any information about nerve function, and it cannot inform the surgeon whether these anatomical changes are the sources of the symptoms ${ }^{14)}$.

Determining whether the herniated disc is the cause of the patient's presenting symptoms is much more challenging when the imaging studies show LDH on the contralateral side of symptoms.

Although rare, $\mathrm{LDH}$ related to contralateral neurologic deficits has been reported by spine surgeons.

In these challenging cases, spine surgeons are confused due to the fact that exact etiology and adequate treatment has not been clarified in the literature. Electrodiagnostic studies may be helpful in this situation because this approach is exquisitely specific; therefore, it is a good complement to MRI, which is a very sensitive, but not specific, test.

Some authors have published reports on contralateral symptoms due to unilateral $\mathrm{LDH}$ and their possible factors (Table 2) $)^{2,4,6,11,12)}$.

Choudhury et al. ${ }^{3)}$ have reported three cases of lumbar radiculopathy contralateral to LDH and they explained, for the first time, that the syndrome may be caused by the prominent spondylotic changes and the accompanying stenosis.

However, Kornberg" has reported 4 patients with LDH, contralateral radiculopathy, with no evidence of spondylotic 
Table 2. Summary of previous reports of LDH presenting contralateral neurologic deficits

\begin{tabular}{|c|c|c|c|}
\hline Study & Year & Patient number & Possible factors \\
\hline Choudhury et al. ${ }^{3)}$ & 1978 & 3 & Enlarged facet, LRS \\
\hline Auld and DeWall' & 1979 & 1 & $\begin{array}{l}\text { Contralateral } \\
\text { compression }\end{array}$ \\
\hline Chou et al. ${ }^{2)}$ & 1986 & 1 & - \\
\hline Shimamura et al. ${ }^{12)}$ & 1991 & 1 & Fibrosis of the root \\
\hline Kornberg ${ }^{9)}$ & 1994 & 4 & $\begin{array}{l}\text { Spondylosis, LRS, } \\
\text { facet hypertrophy }\end{array}$ \\
\hline Miyashita et al. ${ }^{11)}$ & 1998 & 1 & - \\
\hline $\begin{array}{c}\text { Mirovsky and } \\
\text { Halperin }^{10)}\end{array}$ & 2000 & 5 & Eccentric compression \\
\hline Higashi et al.' & 2002 & 1 & Enlarged facet \\
\hline Hayashi and Yoshida4) & 2003 & 1 & - \\
\hline Hasegawa et al.5) & 2005 & 5 & LRS, friction radiculitis \\
\hline Sucu and Gelal ${ }^{13)}$ & 2006 & 5 & $\begin{array}{l}\text { Contralateral traction } \\
\text { force }\end{array}$ \\
\hline Kalemci et al. ${ }^{8)}$ & 2013 & 1 & Venous congestion \\
\hline Yang et al. ${ }^{16)}$ & 2015 & 1 & Migrated epidural fat \\
\hline
\end{tabular}

$\mathrm{LDH}$ : lumbar disc herniation, LRS : lateral recess stenosis

change or stenosis.

In the series reported in Mirovsky and Halperin ${ }^{10)}, 3$ of 5 patients had compression of the contralateral nerve root and both nerve roots were explored by removing the yellow ligament.

However, Sucu and Gelal ${ }^{13)}$ have reported 5 patients with paracentral LDH with the apex deviated away from the side of contralateral symptoms. They proposed that traction force, rather than direct compression, might be responsible for the contralateral symptoms because the traction force generated on the contralateral root is stronger than the force applied on the ipsilateral nerve root. Therefore, they argued that the selective surgical intervention from the herniation side is sufficient $^{13)}$.

Friction radiculitis, migrated epidural fat, nerve root anomaly or venous congestion were also discussed as possible causes of the associated contralateral neurological deficits ${ }^{5,8,16)}$.

In our series, we did not observe any anomaly of the nerve root, epidural lipomatosis or venous congestion. Instead, we found a paracentral herniated disc with the apex deviated away from the side of the symptoms on MRI in 7 of the eight discs. In agreement with Sucu and Gelal ${ }^{13}$, we believe that the traction force generated on the contralateral nerve root, or the lateral recess stenosis, may be responsible for the contralateral symptoms. Lateral recess stenosis may have an effect on contralateral clinical signs. It has been previously postulated that the compression of the neural structures toward the lateral recess on the contralateral side is more frequent if the herniated disc is larger or if the disc material migrates caudally $y^{5}$.

Resolution of symptoms and signs in all patients were achieved. EMG findings and the existence of suspicious contralateral lateral stenosis are important to explore and decompress the symptomatic side in addition to discectomy for herniated disc. In the absence of lateral recess stenosis or radiculopathy on EMG on the symptomatic side, bilateral decompression may not be necessary.

\section{CONCLUSION}

Contralateral neurologic deficits can be caused by LDH. Traction, rather than direct compression, may cause contralateral neurologic deficits in LDH. Electrodiagnosis as well as MRI can play a complementary role in the diagnosis for symptomatic lumbar radiculopathy.

\section{References}

1. Auld AW, DeWall JG : Myelographic defect on the side opposite the leg pain. A case report with an explanation of mechanism of action. Spine (Phila Pa 1976) 4 : 174-175, 1979

2. Chou H, Tsutsumi T, Saito M, Kogame M, Kim T, Asai T : LI/2 disc herniation with flaccid paralysis of contralateral lower cxtremity-a case report. Rinsho Seikei Geka 21 : 107-111, 1986

3. Choudhury AR, Taylor JC, Worthington BS, Whitaker R : Lumbar radiculopathy contralateral to upper lumbar disc herniation : report of 3 cases. Br J Surg 65 : 842-844, 1978

4. Hayashi M, Yoshida A : First and second lumbar disc herniation with symptoms of the contralateral extremity; a case report. Seikeigeka 54 : 1402-1405, 2003

5. Hasegawa T, Imai Y, Katsuno R, Ohnaru K, Saeki T, Mikawa Y : Lumbar radiculopathy contralateral to the side of lumbar disc herniation. Kawasaki Med J 31 : 47-54, 2005

6. Higashi T, Tanimoto M, Honda A, Numazaki S, Tatara Y, Kobayashi A : Single lumbar disc herniation with contralateral two nerve roots involvement : a case report. Seikeigeka 53 : 57-59, 2002

7. Jensen MC, Brant-Zawadzki MN, Obuchowski N, Modic MT, Malkasian D, Ross JS : Magnetic resonance imaging of the lumbar spine in people 
without back pain. N Engl J Med 331 : 69-73, 1994

8. Kalemci O, Kizmazoglu C, Ozer E, Arda MN : Lumbar disc herniation associated with contralateral neurological deficit : can venous congestion be the cause? Asian Spine J 7 : 60-2, 2013

9. Kornberg $M$ : Sciatica contralateral to lumbar disk herniation. Orthopedics $17: 362-364,1994$

10. Mirovsky $Y$, Halperin $N$ : Eccentric compression of the spinal canal causing dominantly contralateral-side symptoms. J Spinal Disord 13 : 174177,2000

11. Miyashita H, Kumano K, Yokozeki $H$ : Sciatica on the opposite side of lumbar disc herniation a case report. Bessatsu Seikei Geka $13: 81$ 82, 1998

12. Shimamura T, Ohsawa Y, Yamaki K, Kaiyama j, Abe M : A case report of lumbar disc herniation with contralateral symptoms. Seikeigeka 42 :
1233-1236, 1991

13. Sucu HK, Gelal F : Lumbar disc herniation with contralateral symptoms. Eur Spine J 15 : 570-574, 2006

14. Weishaupt $D$, Zanetti $M$, Hodler J, Boos $N$ : MR imaging of the lumbar spine : prevalence of intervertebral disk extrusion and sequestration, nerve root compression, end plate abnormalities, and osteoarthritis of the facet joints in asymptomatic volunteers. Radiology 209 : 661-666, 1998

15. Wilberger JE Jr, Pang D : Syndrome of the incidental herniated lumbar disc. J Neurosurg 59 : 137-141, 1983

16. Yang JS, Zhang DJ, Hao DJ : Lumbar disc herniation with contralateral radiculopathy : do we neglect the epidural fat? Pain Physician 18 : 253-256, 2015 